\title{
Spermogram and Male Fertility: Hospital Experience in Military Avicenna of Marrakech
}

\author{
Zemrani $Y^{1, *}$, Taoufik $L^{1}$, Ait Zirri $K^{1}$, Ghoundale $\mathbf{O}^{2}$, EI Mezouari $E^{1}$, Moutaj $\mathbf{R}^{1}$ \\ ${ }^{1}$ Department of Parasitology and Mycology, Military Hospital Avicenne, Faculty of Medicine and Pharmacy, Marrakech, Morocco \\ ${ }^{2}$ Department of urology, Military Hospital Avicenne, Faculty of Medicine and Pharmacy, Marrakech, Morocco \\ *Corresponding author: yassinzemrani@gmail.com
}

Received April 11, 2019; Revised May 14, 2019; Accepted June 08, 2019

\begin{abstract}
Male fertility is known in the last twenty years. Thus, the $1 / 3$ of the infertility of the couple would be male. The spermogram is an essential tool in the strategy of exploration of infertility in humans. The present study will focus exclusively on the place of occupation spermogram in the appearance of the infertile couple. We wrote this retrospective study spread over 10 results of 929 spermograms performed at the Avicenne Military Hospital in Marrakesh, spermogram volume in $\mathrm{ml}, \mathrm{pH}$, sperm count $/ \mathrm{ml}$, spermatozoa vitality, total mobility, progressive mobility and morphology. Of the 929 sperm samples, $35 \%$ on the normal values and $65 \%$ on the normal to less than normal values on the basic parameters, from $65 \%$ to today. Found in $5.4 \%$ of cases, asthenospermia in $46 \%$ of cases, oligospermia in $24.5 \%$ and revelation teratospermia in $21.9 \%$ of cases. After our study, we are confronted like other countries, the problem of male infertility. The spermogram is the essential exam for the exploration of the male side in an infertile couple to make diagnoses, but also the doctor treating additional examinations.
\end{abstract}

Keywords: spermogram - male fertility - couple sterility

Cite This Article: Zemrani Y, Taoufik L, Ait Zirri K, Ghoundale O, El Mezouari E, and Moutaj R, "Spermogram and Male Fertility: Hospital Experience in Military Avicenna of Marrakech." American Journal of Medical Case Reports, vol. 7, no. 6 (2019): 104-108. doi: 10.12691/ajmcr-7-6-3.

\section{Introduction}

The World Health Organization (WHO) defines the infertility of a couple whose wife is of childbearing age as "the inability to conceive or obtain a pregnancy beyond 12 months of intercourse unprotected regular sex. It is called primary when there has never been a pregnancy and secondary if after one or more pregnancies, the woman does not manage to become pregnant when she wishes.

The woman has long been considered the main culprit of conjugal infertility. However, for decades, the progress of medicine in general and those of reproductive biology in particular have established that the responsibility of the man in the infertility of the couple in 20 to $30 \%$ of the cases according to the French epidemiological bases or North American [1]. Infertility is therefore a public health problem and also a serious social problem.

To evaluate male fertility and infertility, the spermogram is the essential test for the exploration of the male side in an infertile couple to make diagnoses, but also to guide the prescriber to further examinations. Our work aims to focus on the place of the spermogram in the exploration of the infertile couple.

\section{Patients and Methods}

We conducted a 10-year retrospective study (from $10 / 08 / 2008$ to $31 / 12 / 2018$ ) involving 929 spermograms performed at the parasitology-mycology department of the Avicenne military hospital in Marrakech. All subjects were advised to abstain from ejaculation for a period of 3 to 5 days. The period of abstinence from ejaculation was calculated as the time elapsed between current and previous ejaculations, as reported by the subjects. Sperm is collected in our laboratory after urination in a sterile plastic container. Sperm samples were anonymous serial number and incubated in the oven at $37^{\circ} \mathrm{C}$ until analysis. All samples were analyzed within 60 minutes of collection.

The study of the spermogram concerns the following criteria: appearance (color, odor), viscosity, volume in $\mathrm{ml}$, and $\mathrm{pH}$, sperm count $/ \mathrm{ml}$, spermatozoa vitality, total mobility, progressive mobility and morphology. Sperm volume was measured after liquefaction of the samples. The sperm count is performed in cells (Malassez or Kova) after homogenization, dilution and immobilization of spermatozoa. The vitality of spermatozoa is obtained after staining of a sample with a vital dye (eosin-nigrosine). Mobility is assessed on a sperm sample between lamella and lamella. Two types of motility were evaluated in this 
study: total mobility and progressive mobility. The morphological analysis of spermatozoa involves the study of the head, the intermediate piece and the flagella after fixation and staining of a sperm smear. Spermoculture is required to complete the examination.

\section{Results and Analyzes}

A total of 929 spermograms were included in our study. The mean age of the study population ranged from 24 to 51 years with an average of 35 years. The spermograms requested were indicated in the assessment of primary infertility in $75 \%$ of cases and in $25 \%$ of cases as secondary. All samples were analyzed within 30 to 60 minutes of collection. The majority of sperm samples were gray or greyish-yellow $(98.2 \%)$, and liquefaction time was less than 60 minutes in $96 \%$ of cases.

The results of spermograms were interpreted according to the criteria of the WHO version 2010 [2] (Table 1) and were as follows: the sperm volume was normal $(\geq 1.5 \mathrm{ml})$ in the majority of cases $(94.5 \%)$ with an average of $2.7 \mathrm{ml}$. $\mathrm{PH}$ values ranged from $7-10$ with normal $\mathrm{pH}$ in $74.2 \%$ of patients.

Table 1. Reference values of sperm parameters

\begin{tabular}{ccccc}
\hline & The anomaly & \multicolumn{3}{c}{ Reference values (OMS } \\
\cline { 3 - 5 } & & $\begin{array}{c}\text { Low } \\
\text { limit }\end{array}$ & Median & $\begin{array}{c}\text { Height } \\
\text { limit }\end{array}$ \\
\hline $\begin{array}{c}\text { Semen volume } \\
(\mathrm{mL})\end{array}$ & $<1,5:$ Hypospermia & 1,5 & 3,7 & 6,8 \\
\hline $\begin{array}{c}\text { Sperm } \\
\text { concentration } \\
\left(10^{6} / \mathrm{mL}\right)\end{array}$ & 0 : Azoospermia & 15 & 73 & 213 \\
\hline $\begin{array}{c}\text { Total motility } \\
(\%)\end{array}$ & $<40:$ Asthenospermia & 40 & 61 & 78 \\
\hline $\begin{array}{c}\text { Progressive } \\
\text { motility }(\%)\end{array}$ & $<32:$ Asthenospermia & 32 & 55 & 72 \\
\hline Vitality $(\%)$ & $<58 \%:$ Necrospermia & 58 & 79 & 91 \\
\hline Normal forms $\%$ & $<4:$ Teratospermia & 4 & 15 & 44 \\
\hline
\end{tabular}

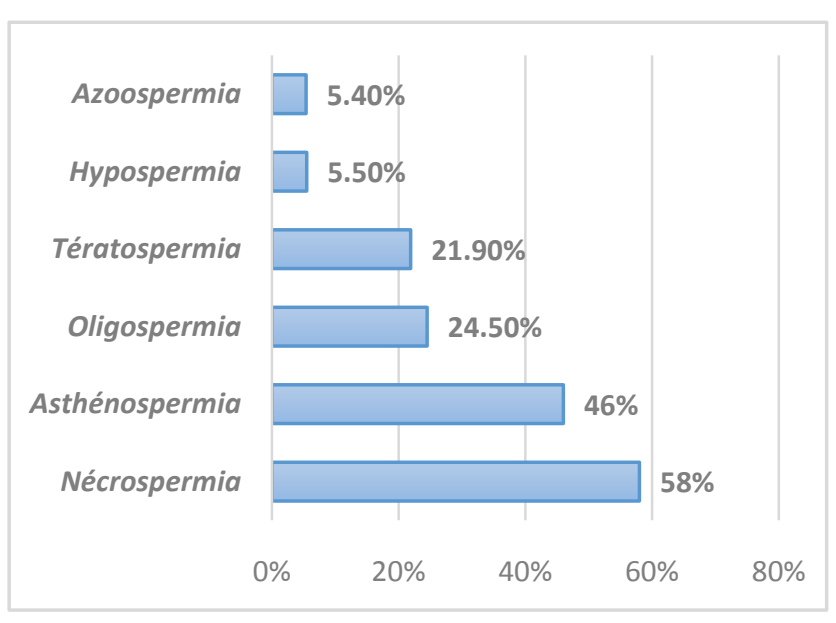

Figure 1. Distribution of patients according to the spermiological profile

Oligospermia was found in $24.5 \%$ of patients while azoospermia occurred in only $5.4 \%$ of cases. Total mobility was $\leq 40 \%$ in $29.4 \%$ of patients, whereas progressive mobility could not reach the normal threshold $(\geq 32 \%)$ in $62.7 \%$ of our patients, so asthenospermia estimated on average at $46 \%$. Sperm vitality was $\geq 58 \%$ in $42 \%$ of patients, which represents a necrosospermia rate of $58 \%$. 23 patients $(2.4 \%)$ had leukocyte levels above normal ( $\leq 1$ million leukocytes / $\mathrm{ml})$. The normal sperm morphology was in normal values in $88.1 \%$ according to WHO criteria, so teratospermia was revealed in $21.9 \%$ of cases.

Of the 929 sperm samples evaluated, 35\% displayed normal sperm parameters according to the WHO criteria, but $65 \%$ had values below the normal threshold in at least one of the sperm parameters, including sperm volume. , sperm concentration, total number, vitality, mobility and normal morphology.

\section{Discussion}

Having a healthy sexuality and motherhood, being a parent, are social necessities. Infertility is defined as the absence of pregnancy after more than 12 months of regular sexual intercourse without contraception. It affects about $15 \%$ of couples of childbearing age. Male or mixed causes account for about $50 \%$ of infertility [3]. A decrease in semen quality was observed as early as 1980, then confirmed by Meta-analyzes and weighted by taking into account different methodological and environmental factors [4]. In a large recent Danish study, 35.6\% of men's infertility etiologies remained unexplained [5]. Recent data from the literature suggest hypotheses about the impact of epigenetics, body mass index (BMI) and lifestyle on reproductive function [6]. These consequences are all the more important since the epigenetic changes in sperm seem to be transmitted to offspring: this is the transgenerational effect. In addition, sperm quality may reflect men's health status [7].

Spermatogenesis is a complex and continuous process in which spermatogonia, diploid stem cells, differentiate into spermatocytes during mitosis and then into spermatocytes II, during meiosis and then into round spermatids. It is only after release of spermatide in the lumen of the tubule that the cell takes the name of "spermatozoid", male gamete haploid. In humans, spermatogenesis begins at puberty and is then continuous throughout life. It is carried out within the epithelium of the testicular seminiferous tubes, in which the Sertoli cells serve as their physical and nourishing support. It lasts 74 days and allows a production of about 200 million sperm per day. A defect of this process can lead to an anomaly of number, mobility, morphology or vitality. Thus each abnormality of spermatogenesis has to be confirmed on 2 samples at 3 month intervals, due in part to the great variability of the spermatic parameters and also to the cycle of spermatogenesis [7].

The analysis of the spermogram should be done according to the time of abstinence. The classic delay of 2 to 7 days is important from the first spermogram [8]. The longer abstinence period can lead to an increase in the volume of the ejaculate, the concentration and the total number of spermatozoa collected. But it can be responsible for a decrease of the spermatic mobility as well as an alteration of the number of typical forms with spermocytogram. Conversely, a shortened abstinence period decreases the count and increases sperm motility [9]. 
Sometimes noted in the first spermogram, an increase in sperm viscosity may interfere with the determination of sperm motility and concentration. They may be of prostatic origin or secondary to the use of a plastic vial unsuitable for sperm collection [10]. There was no correlation between seminal hyperviscosity, positivity of sperm cultures, leukospermia or the presence of anti-sperm antibodies in sperm [11]. However, an increased rate of failure of in vitro fertilization has been described in the case of seminal hyperviscosity [12]. In an attempt to remedy this, it is possible to predict either a greater fluid intake in the days preceding the collection, or the collection of the ejaculate in a culture medium [10]. Treatment of sperm before intrauterine insemination (IUI) may be considered if there is a clinical problem of hyperviscosity [13].

In our study, the $\mathrm{pH}$ in the normal range $(\mathrm{pH}=7-8)$ is $73.8 \%$. The $\mathrm{pH}$ should be between 7.2 and 8 and tends to increase with time after ejaculation. Increased $\mathrm{pH}$ evokes prostate involvement and decreased $\mathrm{pH}$ suggests involvement of vas deferens or seminal vesicles. A low volume sample with a measured $\mathrm{pH}$ below 7.0 indicates ejaculatory blockage. A change in $\mathrm{pH}$ may also be due to incomplete collection $[10,14]$.

A normal sperm volume $(\geq 1.5 \mathrm{ml})$ was found in $94.5 \%$ of our patients. Hypospermia corresponds to an ejaculate volume of less than $1.5 \mathrm{~mL}$ on at least two successive spermograms. The causes of hypospermia are numerous and can be divided into two pathophysiological groups: disturbances of the ejaculation reflex resulting in a partial retrograde ejaculation and anatomic (uni- or bilateral deferens agenesis of the vas deferens) and functional (low plasma testosterone) lesions.) glands and seminal ways. In the latter group, mutations in the Cystic Fibrosis Transmembrane Regulator (CFTR) gene, implicated in forms of variable severity of cystic fibrosis, represent a possible cause of hypospermia. The detection of molecular abnormalities of this gene before any hypospermia represents a major stake for the potential progeny of the couple, but also for the patient himself in more or less long term. Treatment of the cause of hypospermia if it does not compromise the subsequent fertility of the patient will be considered as soon as possible [15]. While a volume $>6 \mathrm{ml}$ may be due to too long abstinence or hypersecretion prostatic and vesicular (infection). Remember that the seminal vesicles produce most of the volume of the seminal fluid [2]. However, the increase in seminal volume could not influence sperm parameters, with the exception of the number of sperm [16].

Almost one-third of patients have oligospermia (24.5\%), azoospermia is found in $5.4 \%$, while azoospermia requires a complete clinical and paraclinical assessment to understand its origin, particularly obstructive genital tract) or non-obstructive (lack of testicular production). The distinction is based on a bundle of clinical, spermiological, hormonal, ultrasonographic, genetic and histological data. Azoospermia is the main indication for testicular biopsy for therapeutic and diagnostic purposes [17,18].

The percentage of mobility is the parametric parameter of the spermogram: it partly determines the therapeutic orientation. Indeed, only sperm with normal progressive mobility can reach and penetrate the oocyte. Asthénospermie is estimated on average at $46 \%$ in our study, which is extremely worrying. Sperm motility is acquired during epididymal transit. Sperm movement is important for migration from the vagina to the fallopian tubes, for penetration into cumulus oophorus and for processes involved in fertilization. Thus, there is an association between sperm mobility and the chances of conceiving naturally [19]. In the interpretation of asthenospermia and apart from cases where abstinence or viscosity are very important, it can be explained either by the presence of flagellary alterations of genetic or congenital origin with viable but immobile spermatozoa, or by necrozoospermia secondary to genital infections, oxidative stress, the presence of antispermatozoids [20], alterations in ATP production [21], toxic exposure [22], abnormalities of epididymal transport of spermatozoa [23], or anejaculation.

The sperm count in sperm is hardly synonymous with its good quality, indeed a sperm may seem to contain enough sperm, but more than half may be dead after staining with eosin or a hypoosmotic test of spermatozoa. Flagellar coil. In fact, $58 \%$ of our patients suffer from necrosospermia. This anomaly may be due to too long a period of abstinence or a failure to comply with the recommendations for semen collection, two situations requiring a second spermogram. If confirmed, several pathological mechanisms may be responsible for necrozoospermia. They may be of testicular origin (hyperthyroidism, varicocele, hyperthermia), posttesticular (epididymal necrozoospermia, seminal plasma abnormality, polycystic kidney, post vaso-vasostomy, anti-spermatozoid antibodies) or mixed (infection, toxic, age, injured spinal cord). Treatment is primarily etiological when possible. Fertilization rates are low in cases of necrozoospermia, but in vitro fertilization techniques with intracytoplasmic sperm microinjection improve the chances of conception [24].

Spermocytogram is the examination of sperm morphology after staining slides. Sperm morphology is heterogeneous between individuals and in the same individual, whether fertile or not. If one looks at the data of the literature on more than 30 years of publications, the origin and the impact of many traits or morphological "anomalies" remain unclarified probably because there is a physiological character in the appearance of these anomalies [25].

Although morphological evaluation of the spermatozoon is an integral part of the spermogram and the infertility assessment of the couple, its correlation with fertility remains controversial: most studies show that sperm morphology can be predictive of natural fertility $[26,27]$ intrauterine insemination [28,29], as well as classical in vitro fertilization (IVF) [30,31], but the same is not true of intracytoplasmic sperm injection (ICSI), where the literature review contradictory results. Apart from the gross anomalies of the spermatic heads (macro- or microcephalic, globozoospermia ...) which are associated with fertilization failures and which do not give or very exceptionally pregnancies, it has not been frankly highlighted. Relationship between percent of normal forms and ICSI results: for some authors, fertilization and pregnancy rates are similar for teratospermia and normal sperm $[32,33,34,35]$.

As is the case in our study, the decline in spermogram parameters in different countries around the world remains 
an undeniable fact $[36,37,38,39]$. These countries even advocate the installation of the centers just for monitoring the evolution of male fertility. The intervention of other parameters not yet incriminated until our days is discussed more and more. In addition to conventional medicosurgical causes, tobacco, endocrine disruptors and medications would be an important cause among others for the alteration of human sperm $[7,40,41,42,43]$.

\section{Conclusion}

The steady decline in male fertility over time is proving to be a global scourge and is attracting more and more interest from scientists. Morocco would certainly not be spared as our study shows, although it is conducted on a small scale at the locoregional level and the increasing number of couples using the PMA. Today, biologists will be confronted more than ever with this problem and will have to deal with it thanks to a good knowledge of spermograms and spermocytograms in laboratories and their interpretation, as well as ongoing training on the management of sterile couples from the anamnesis to the prescription of complementary examinations pushed in collaboration with the clinicians to prescribe the treatment adapted to each situation.

\section{References}

[1] Meacham $\mathrm{r}$ b, Joyce $\mathrm{g} f$, Wise $\mathrm{m}$, et al . Male Infertility. J Urol 2007; 177: 2058-66.

[2] Trevor G. Cooper, Elizabeth Noonan, Sigrid von Eckardstein, Jacques Auger, H.W. Gordon Baker, Hermann M. Behre, Trine B. Haugen, Thinus Kruger, Christina Wang, Michael T. Mbizvo, and Kirsten M. Vogelsong. World Health Organization reference values for human semen characteristics. Human Reproduction Update, Vol.00, No.0 pp. 1-15, 2009.

[3] Inhorn MC, Patrizio P. Infertility around the globe: new thinking on gender, reproductive technologies and global movements in the 21st century. Hum Reprod Update 2015;21:411-26.

[4] Jørgensen N, Joensen UN, Jensen TK, Jensen MB, Almstrup K, Olesen IA, et al. Human semen quality in the new millennium: prospective cross-sectional population-based study of $4867 \mathrm{men}$. BMJ Open 2012;2(4).

[5] Olesen IA, Andersson A-M, Aksglaede L, Skakkebaek NE, Rajpert-de Meyts E, Joergensen N, et al. Clinical, genetic, biochemical, and testicular biopsy findings among 1,213 men evaluated for infertility. Fertil Steril 2017; 107: 74-82.e7.

[6] Salas -Huetos A, Bulló M, Salas-Salvadó J. Dietary patterns, foods and nutrients in male fertility parameters and fecundability: a systematic review of observational studies. Hum Reprod Update 2017; 23: 371-89.

[7] Sophie Lamothea, Véronique Kerlanc, Sophie Christin-Maitrea, Qualité du sperme et fertilité : rôle de l'environnement et de la santé. Annales d'Endocrinologie 79 (2018) S1-S9.

[8] Pellestor F, Girardet A, Andrea B. Effect of long abstinence periods on human sperm quality. Int J Fertil Menopausal study 1994; 39: 278-82,

[9] Jurema MW, Vieira AD, Bankowski B, Petrella C, Zhao Y, Wallach E, Zacur H. Effect of ejaculatory abstinence period on the pregnancy rate after intrauterine insemination Fertil Steril 2005; 84: 678-81.

[10] Vasan, S. S. Interpretation of Semen Analysis. Male Infertility (2016), 55-83.

[11] Munuce MJ, Bregni C, Carizza C, Mendeluk G. Semen culture, leukocytospermia and the presence of sperm antibodies in seminal hyperviscosity. Arch Androl. 1999; 42: 21-8.

[12] Esfandiari N, Burjaq H, Gotlieb L, Casper RF. Seminal hyperviscosity is associated with poor outcome of in vitro fertilization and embryo transfer: a prospective study. Fertil Steril. 2008; 90: 1739-43.

[13] A. Devaux, P. Demailly, R. Cabry, F. Brasseur, E. Lourdel, C. Clayes, M.-F. Ollieric, H. Copin, P. Merviel. Valeurs limites du spermogramme : comment les interpreter ? Quelle conduite adopter? Gynécologie Obstétrique \& Fertilité 38 (2010) 16-17.

[14] N.Belhadrie-Mansouri; N. Celton; A. Devaux; H. Copin; P Merviel, M.Benkhalifa. Lecture du spermogramme, du spermocytogramme et techniques d'analyses du génome du spermatozoïde. Infertilité; Prise en Charge Globale et Thérapeutique 2016, Pages 65-70.

[15] G. Robin, F. Marcelli, V. Mitchell, C. Marchetti, L. Lemaitre, D. Dewailly, M. Leroy-Billiard, J.-M. Rigot. Pourquoi et comment réaliser un bilan d'hypospermie ? Gynécologie Obstétrique \& FertilitéVolume 36, Issue 10, October 2008, Pages 1035-1042.

[16] Yue-juan ZHANG ;Jian ZHONG ;Wei-jie ZHU. Evaluation on sperm parameters of ejaculates with hyperspermia. Journal of Reproduction and Contraception. Volume 26, Issue 3, September 2015, Pages 131-134

[17] Geoffroy Robin ; Florence Boitrelle ; Xavier Leroy ; Marie-Claire Peers ;François Marcelli ; Jean-MarcRigot ; Valérie Mitchell ; Bilan d'une azoospermie et évaluation histologique de la spermatogenèse. Annales de PathologieVolume 30, Issue 3, June 2010, Pages 182-195

[18] E. Amar. Du bilan standard aux examens spécialisés chez l'homme infertile. Gynécologie Obstétrique \& Fertilité 38 (2010) $8-9$

[19] Beauchamp PJ, Galle PC, Blasco L. Human sperm velocity and postinsemination cervical mucus test in the evaluation of the infertile couple. Arch Androl 1984; 13: 107-12.

[20] Lee R, Goldstein M, Ullery BW, Ehrlich J, Soares M, Razzano RA, et al. Value of serum antisperm antibodies in diagnosing obstructive azoospermia. J Urol 2009; 181: 264-9.

[21] Folgerø T, Bertheussen K, Lindal S, Torbergsen T, Oian P. Mitochondrial disease and reduced sperm motility. Hum Reprod 1993; 8: 1863-8

[22] Hauser R, Sokol R. Science linking environmental contaminant exposures with fertility and reproductive health impacts in the adult male. Fertil Steril 2008; 89: e59-65.

[23] Wilton LJ, Temple-Smith PD, Baker HW, de Kretser DM. Human male infertility caused by degeneration and death of sperm in the epididymis. Fertil Steril 1988; 49: 1052-8.

[24] A. Dumont A. -L. Barbotin V. Lefebvre-Khalil V. Mitchell J.-M. Rigot F. Boitrelle G. Robin. La necrozoospermie: du diagnostic étiologique à la prise en charge thérapeutique. Gynécologie Obstétrique Fertilité \& Sénologie; Volume 45, Issue 4, April 2017, Pages 238-248.

[25] Gatimel N, Moreau J, Parinaud J, et al. Sperm morphology: assessment, pathophysiology, clinical relevance, and state of the art in 2017. Andrology. 2017; 5(5): 845-62.

[26] Bartoov B, Eltes F, Pansky M, Lederman H, Caspi E, Soffer Y. Estimating fertility potential via semen analysis data. Hum Reprod 1993; 8: 65-70.

[27] Van der merwe FH, kruger TF, Oehninger SC, Lombard CJ. The use of semen parameters to identify the subfertile male in the general population. Gynecol Obstet Invest 2005; 59: 86-91

[28] Van Waart J, Krugert F, Lombard CJ, Ombelet W. Predictive value of normal sperm morphology in intrauterine insemination (IUI): a structured literature review. Hum Reprod Update 2001; 7 : 495-500.

[29] Lee RK, Hou JW, Ho HY, et al. Sperm morphology analysis using strict criteria as a prognostic factor in intrauterine insemination. Int J Androl 2002; 25: 277-80.

[30] Kruger TF, Acosta AA, Simmons KF, Swanson JR, Matta JF, Oehninger S. Predictive value of sperm morphology in in vitro fertilization. Fertil Steril 1988; 49: 112-7.

[31] Coetzee K, Kruge TF, Lombard CJ. Predictive value of normal sperm morphology: a structured literature review. Hum Reprod 1998; 4: 73-82.

[32] Lundin K, Soderlund B, Hamberger L. The relationship between sperm morphology and rates of fertilization, pregnancy and spontaneous abortion in an in vitro fertilization/intracytoplasmic sperm injection programme. Hum Reprod 1997; 12: 2676-81.

[33] Keegan B, Barton R, Sanchez S, Berkeley XA, Krey SL, Grifo CJ. Isolated teratozoospermia does not affect in vitro fertilization outcome and is not an indication for intracytoplasmic sperm injection. Fertil Steril 2007; 88: 1583-8. 
[34] French BD, Sabanegh SE, Goldfarb J, Desai N. Does severe teratozoopermia affect blastocyst formation, live birth rate, and other clinical outcome parameters in ICSI cycles? Fertil Steril 2009

[35] Hotaling JM, Smith JF, Rosen M, et al. The relationship between isolated teratozoospermia and clinical pregnancy after in vitro fertilization with or without intracytoplasmic sperm injection: a systematic review and meta-analysis. Fertility and sterility. 2011; 95(3): 1141-5.

[36] Niels E, Skakkebæk, Jørgensen N, Katharina M. Is human fecundity declining?.international journal of andrology 2006;29:211.

[37] Priskorn L, Holmboe SA, Jørgensen N, Andersson AM, Almstrup $\mathrm{K}$. Adverse trends in male reproductive health and decreasing fertility rates. Anim. Reprod 2012; 4: 760-71.

[38] Jørgensen N, Vierula M, Jacobsen R, Pukkala E, Perheentupa A, Virtanen HE, Skakkebæk NE, Toppari J. Recent adverse trends in semen quality and testis cancer incidence among Finnish men. Int J Androl 2011; 34: 37-48.
[39] Iwamoto T, Nozawa S, Mieno MN, Yamakawa K, Baba K, Yoshiike M, Namiki M, Koh E, Kanaya J, Okuyama A, Matsumiya K, Tsujimura A, Kanetake H, Eguchi J, Skakkebaek NE, Vierula M, Toppari J, Jørgensen N. Semen quality of 1559 young men from four cities in Japan: a cross-sectional populationbased study. BMJ Open 2013; 3: 29.

[40] Tawadrous GA et al. Effect of smoking status on seminal parameters and apoptotic markers in infertile men. J Urol 2011; 186: 1986-90.

[41] Ramlau-Hansen CH, Thulstrup AM, Storgaard L, Toft G, Olsen J, Bonde JP. Is prenatal exposure to tobacco smoking a cause of poor semen quality? A follow-up study. Am J Epidemiol 2007; 15: 1372-1379.

[42] Sharpe RM. Environmental/lifestyle effects on spermatogenesis. Philos Trans R Soc Lond B Biol Sci 2010; 365: 1697-712.

[43] Sharma R, Harlev A, Agarwal A, Esteves SC. Cigarette Smoking and Semen Quality: A New Meta-analysis Examining the Effect of the 2010 World Health Organization Laboratory Methods for the Examination of Human Semen. Eur Urol. 2016 Oct; 70(4): 635-645.

(C) The Author(s) 2019. This article is an open access article distributed under the terms and conditions of the Creative Commons Attribution (CC BY) license (http://creativecommons.org/licenses/by/4.0/). 